كفاءة استخدام الموارد في انتاج أهم أصناف العنب بالأراضي الجديدة بمحافظة البحيرة

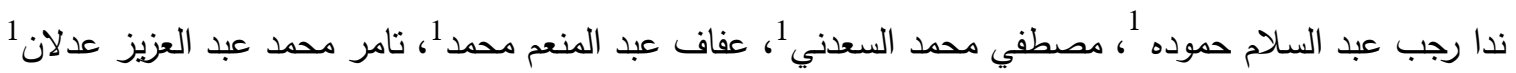

ووجود تأثيرإيجابي معنوي إحصائيا لكل من المغذيات الورقية

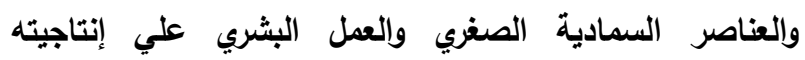
الفدانية، وقد تبين من المرونة الإجمالية للادلة والمقدرة بحوالي 2.3 وجود ظاهرة تزايد العائد للسعة أي أن إنتاج العب صنف الإلف

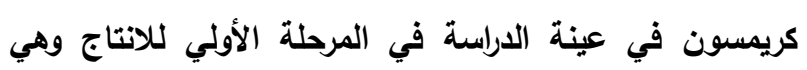
المرحلة غير الاقتصادية.

وتبين من تقدير دالة إنتاج الغتب البناتي وجود تأثير إيجابي

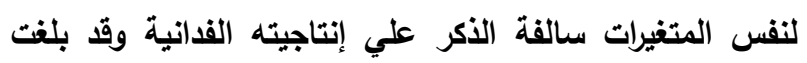

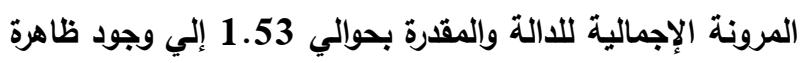

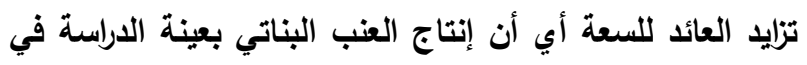
المرحلة الأولي للإنتاج وهي المرحلة غير الإقتصادية.

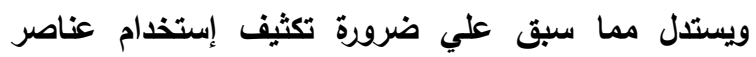

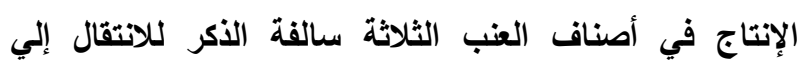
المرحلة الإقتصادية للإنتاج وهي المرحلة الثانية.

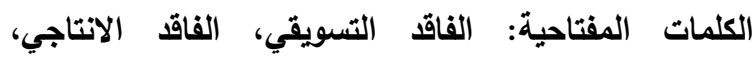

التكاليف التسويقية.

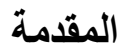

يعتبر العنب من الفاكهة المرغوبة والمحبية لمختلف الطبقات ويأتي في المرتبة الثانية بعد الموالح من حيث أهميته

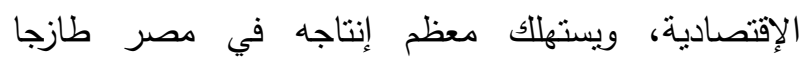

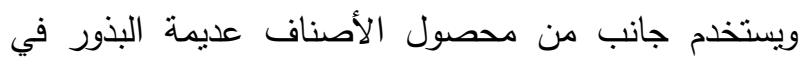
تجفيف وتصنيع الزبيب بينما نوجه بعض الكميات لتصنيع العصير الطازج وتتوفر للعنب المصري ومنتاجاته إمكانية

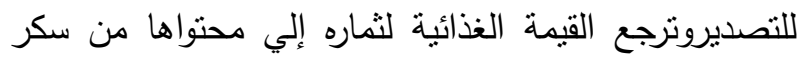
الجلوكوز سهل الإمتصاص بالإضافة إلي مكوناتها الحيوية من العناصر المعدنية المجهزة في صورة صالحة للاستفادة منها وحض الفوليك بجانب بعض المعادن A,B,C فثمار

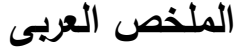

تتمثل مشكلة البحث في الثبات النسبي لانتاجية العنب في

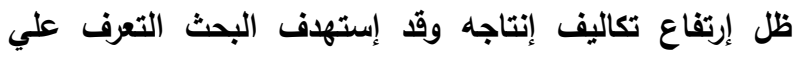

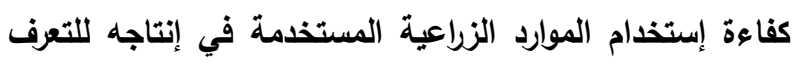

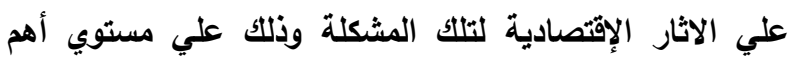
الأصناف المزروعة به في الأراضي الجليدة بمحافظة البحيرة.

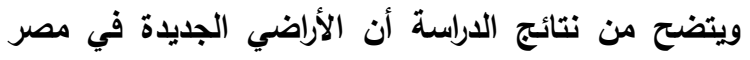
تساهم بنحو68.7\% من إنتاج العنب في مصر وتساهم الأراضي القيمة بحوالي 31.3\% ، كما يتضح من الدراسة أن إنتاج العنب البناتي يمثل حوالي 2.4\% من إجمالي إنتاج العب في كي

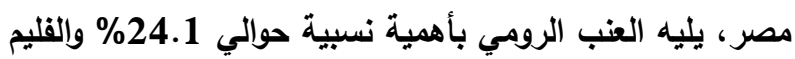

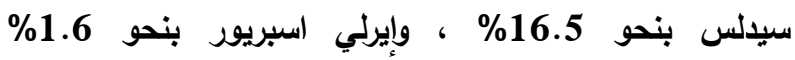
والكريمسون بنحو 1.2\% وكل من الفيومي والبلاي بنحو 0.9 يلي ذلك بمساهمة باقي الأصناف الأخري بنسبة ضئيلة. ويتضح من المؤثرات الإقتصادية لعينة الدراسة والتي إثتملت

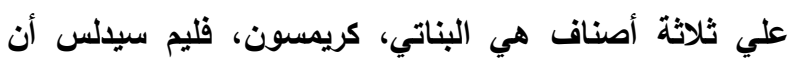
صافي عائد الفدان من العنب البناتي بلغ حوالي 29411 جنيانيان للكريمسون، وحوالي 24763 للفليم سيدلس، وحوالي 13307 للبناتي ويلغت أريحية الجنيه المتفق لكل منهما حوالي 51.5\%

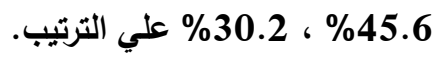

وتبين من تقدير دالة إنتاج الغنب صنف سيلس وجود تأثير إيجابي مغنوي إحصائيا لكل من السماد العضوي والسماد الفوسفاتي والأزوتي والبوتاسي علي الإتتاجية الفانية، كما تبين

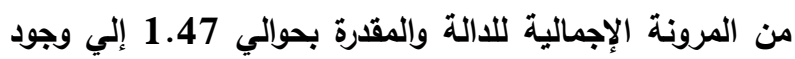
ظاهرة تزايد العائد للسعة أي أن إنتاج العنب فليم سيدلس في الإنية عينة الدراسة في المرحلة الأولي للانتاج غير الإقتصادية. وتبين من تقير دالة إنتاج العنب صنف كريمسون وجود تأثير إيجابي معنوي إحصائيا لنفس المتغيرات سالفة الذكر كريسر وجن

معرف الوثيقة الرقمي: 10.21608/asejaiqjsae.2022.219471 1قنم الاقتصاد والإرشاد الزراعي والتتمية الريفية بكلية الزراعة جامعة دمنهور استلام البحث فى 10يناير 2022، الموافقة على النشر فى 13 فبراير 2022 
79.4 ألف فدان إلى حوالى 123.3 ألف فدان أي بنسبة 55.3 خلال الفترنيين سالفتا الذكر.

كما تتمثل المشكلة البحثية من جانب أخر في التباين الثديد في الإنتاجية الفدانية للعنب سواءاً فيما بين المحافظات وفيما بين الاصناف وهو ما يستلزم التعرف على كفاءة استخدام الموارد لأهم تللك الأصناف للاستتاد اليها في اتخاذ

$$
\text { القرارات المزرعية. }
$$

\section{الأهداف البحثية}

استهدفت هذه الدراسة مايلي:

(1) التعرف علي نظور المؤثرات الإقتصادية المؤثرة علي إنتاج العنب علي مستوي الجمهورية ومحافظة البحيرة وعلي مستوي الأراضي الجديدة والقديمة في كل منها

$$
\text { خلال الفترة (2000-2019). }
$$

(2) التعرف علي المؤشرات الاقتصادية لانتاج العنب بعينة الدراسة بمحافظة البحيرة.

دراسة الأهمية النسبية لكل من الرقعة المزروعة و الإنتاجية والإنتاج لمختلف أصناف العنب.

(4) التقدير القياسي لدوال الإنتاج لأهم أصناف العنب بعينة الدراسة بالأراضي الجديدة بمحافظة البحيرة للتعرف علي كفاعة إستخدام الموارد الزراعية المستخدمة في إنتاج كل بل بهرهي منها بجانب التعرف علي بعض المؤشرات الإقتصادية لكفائته الإقتصادية. الأسلوب البحثي ومصادر البيانات: تستتد الدراسة بجانب إستخدام أسلوب التحليل الإقتصادي الوصفي إلي بعض الأساليب القياسية المتمثلة في الإنحدار البسيط للتعرف علي معدل نمو مختلف المتغيرات الإقتصادية المرتبطة بمجال الدراسة وكذلك أسلوب الإنحدارالمتعدد لتقديردوال الإنتاج لأهم أصناف العنب. لأبهال وقد إستتدت الدراسة إلي البيانات الثانوية المنشورة والمتحصل عليها من نشرات قطاع الشئون الإقتصادية بوزارة
العنب غنية بعناصر غذائية هامة المتمنلة بفيتامينات الضرورية لجسم الانسان مثل البوتاسيوم والكالسيوم والفسفور والحديد والماغنسيوم ،كما أنه غني بالطاقة حيث يحتوي كل 150 جرام منه علي حوالي 104 سعر حراري، وتوفر هذه الكمية حوالي 2\% من الإحتياجات اليومية للبروتين، وحوالي 5 من الألياف ، كما يحتوي العنب علي مضادات الأكسدة التي تحمي الثقوق الحرة التي تقوم بتدمير خلايا الجسم (البهائي.2018)

وتبلغ المساحة المزروعة بالعنب المثمر في مصر حوالي 174.7 ألف فدان نمثن حوالي12\% من المساحة المثرة بمختلف أنواع الفاكهة في مصر عام 2019 والبالغة حوالي 1451.7 ألف فدان ويقدر انتاج العنب من نلك المساحة بحوالي 1595 ألف فدان، وتساهم الأراضي الجديدة بنحو 71.4 من هذا الإنتاج في حين تساهم الأراضي القديمة بنحو 28.6\% منه. وتبلغ إجمالي المساحة المزروعة به في هي محافظة البحيرة في كل من الأراضي القديمة والجديدة حوالى الى بلى 97.6 ألف فدان تمنل حوالي 55.9\% من نظيرتها على مستوي الجمهورية (عطية2005)، وقد بلغ المتوسط السنوي لكمية الصادرات المصرية من العنب حوالى 135 ألف طن تمثل حوالى 18.7\% من إنتاجه المحلي، وبلغت قيمتها التصديرية حوالى 229.8 مليون دولار في منوسط الفترة

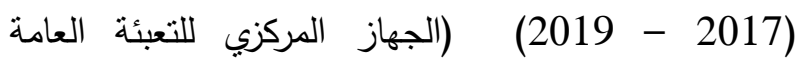
والإحصاء).

\section{المشكلة البحثية}

تتمثل مشكلة البحث في الثبات النسبي للانتاجيه الفدانية للعنب في كلا من الأراضي القديمة والجديدة في ظل ارتفاع تكاليف انتاجه، وهو ما ترتب عليه تراجع المساحة المزروعة به في الأراضي القديمة من حوالى 67.7 ألف فدان في متوسط الفترة (2005 - 2007) إلى حوالى 56.6 ألف فدان في منوسط الفترة (2017 - 2019) أي بنسبة 16.4\% ، في حين نزايدت في الأراضي الجديدة من حوالى 
حوالي 94\% من إجمالي مساحة العنب المثمر في مصر عام 2019. وتمثل المساحة المزروعة بالعنب المثمر في موك منطقة النوبارية حوالي 56.6\% من إجمالي الجمهورية، يليها محافظة المنيا بأهمية نسبية حوالي روباله 13.78 ، والغربية بحوالي 6.19\% والبحيرة حوالي 5.22\% ، والدقهلية وبني سويف بحوالي 3.56\% لكل منهما، والجيزة بحوالي

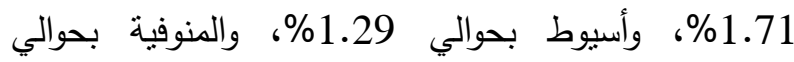

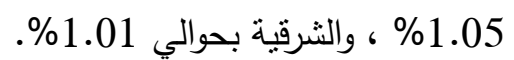
كما يتضح من جدول (1) تباين الإنتاجية الفدانية في تلك المحافظات حيث بلغت حدها الأدني في محافظة المنيا بحوالي 7.386 للفدان وحدها الأعلي في محافظة أسيوط بحوالي 13.019 طن للفدان وبمتوسط عام للجمهورية بلغ حوالي 9.128 طن للفدان. كما تبين أن الانتاجية الفدانية من العنب في محافظات الاسكندرية، الغربية، الدقهلية، المنوفية، الجيزة، المنيا أقل من المتوسط العام لنظيرتها علي مستوي

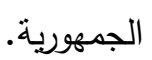

الزراعة واستصلاح الأراضي ونشرات الجهاز المركزي للتعبئة العامة والإحصاء. وكذلك البيانات غير المنشورة المتحصل عليها من مديرية الزراعة بمحافظة البحيرة ومديرية الزراعة بالنوبارية هذا بجانب البيانات الأولية المتحصل عليها من إستمارات الإستبيان التي أجري تجمعيها من زراع عينة الدراسة والبالغ حجمها مائة وخمسون مزارعا من زراع العنب من قري مراقبة غرب النوبارية بمنطقة النوبارية التي نتبع إداريا محافظة البحيرة. وكذللك تم الاستعانة ببعض الدراسات والبحوث الاقتصادية الزراعية ذات الصلة بموضوع البحث.

\section{النتائج البحثية والمناقشة}

الأهمية النسبية للمحافظات المصرية في إنتاج العنب يتضح من جدول (1) أن المساحة المزروعة بالعنب المثر في مصر تتركز في إحدي عشر نطاق جغرافي هي منطقة النوبارية ومحافظات الاسكندرية،البحيرة، الغربية، الدقهلية، الثرقية، المنوفية، الجيزة، بني سويف، المنيا، أسيوط حيث تمثل المساحة المزروعة بالعنب فيها مجتمعه

جدول 1. جدول مساحة وانتاجية وانتاج من محصول العنب في محافظات جمهورية مصر العربية لعام 2019 (المساحة بالقدان والانتاجية بالطن / فدان والانتاج بالطن

\begin{tabular}{|c|c|c|c|c|c|c|}
\hline \multicolumn{2}{|c|}{ الإنتاج } & \multicolumn{2}{|c|}{ الانتاجية } & \multicolumn{2}{|c|}{ المساحة المثمرة } & \multirow{2}{*}{ المحافظات } \\
\hline$\%$ & الكمية & $\%$ & الكمية & $\%$ & المساحة & \\
\hline 0.22 & 3448 & 86.63 & 7.908 & 0.25 & 436 & الاسكندرية \\
\hline 6.77 & 107904 & 129.59 & 11.829 & 5.22 & 9122 & البحيرة \\
\hline 5.93 & 94549 & 95.83 & 8.747 & 6.19 & 10809 & الغربية \\
\hline 3.30 & 52614 & 92.79 & 8.47 & 3.56 & 6212 & الدقهلية \\
\hline 1.01 & 16183 & 100.56 & 9.179 & 1.01 & 1763 & الشرقية \\
\hline 1.01 & 16052 & 95.99 & 8.762 & 1.05 & 1832 & المنوفية \\
\hline 1.51 & 24071 & 88.43 & 8.072 & 1.71 & 2982 & الجيزة" \\
\hline 3.69 & 58793 & 103.51 & 9.448 & 3.56 & 6223 & بنى سويف \\
\hline 11.15 & 177762 & 80.92 & 7.386 & 13.78 & 24068 & المنيا \\
\hline 1.84 & 29423 & 142.63 & 13.019 & 1.29 & 2260 & آسيوط \\
\hline 60.73 & 968483 & 107.48 & 9.811 & 56.50 & 98709 & النوبارية \\
\hline 2.85 & 45500 & 48.39 & 4.417 & 5.89 & 10299 & محافظّات آخري \\
\hline 100.00 & 1594782 & 100.00 & 9.128 & 100.00 & 174715 & اجمالى الجمهورية \\
\hline
\end{tabular}


النوبارية وقد تضمنت العينة ثناثة أصناف من العنب السائد زراعتها بتلك المنطقة وهي أصناف فليم سيدلس، كريمسون، البناتي باجمالي 150 مزارع بمعدل 50 مزارع من كل صنف به بهن من الأصناف الثناثة.

التطور الزمني للمساحة المزروعة بالعنب في كل من الأراضي القديمة والجديدة علي مستوي الجمهورية ومحافظة البحيرة خلال الفترة (2005-2019) أولا : المساحة المزروعة بالعنب المثمر: تراوحت إجمالي المساحة المزروعة بالعنب المثمر في مصر خلال الفترة (2005-2019) بين حد أدني حوالي 144.6 ألف فدان عام 2005 وحد أعلي حوالي 186.1 ألف فدان عام 2017 وبمتوسط سنوي بلغ حوالي 163.3 ألف فدان خلال فترة الدراسة. وتساهم الأراضي الجديدة فيها

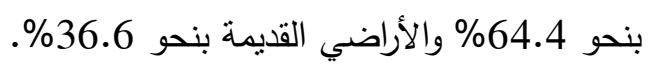
كما تراوحت المساحة المزروعة بالعنب المثر علي

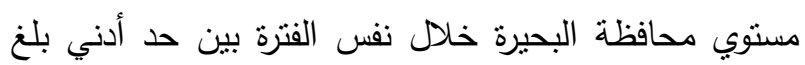
حوالي 5185 فدان عام 2006 وحد أعلي حوالي 10585 فدان عام 2017 وبمتوسط سنوي بلغ حوالي 7696 فدان خلال فترة الدراسة وتناهم الأراضي الجديدة بالمحافظة بنحو 67.4 من تللك المساحة في حين تساهم الأراضي القديمة بالهة

$$
\text { بنحو 32.6\% منها. }
$$

ويتضح من جدول (3) أن المساحة المزروعة بالعنب المثر علي مستوي الجمهورية خلال الفترة (2005-2019) أخذت إتجاها تزايديا معنوي إحصائيا بحوالي 2941 فدان سنويا وبمعدل تغير سنوي حوالي 1.8\% وأخذت نظيرتها علي مستوي محافظة البحيرة إتجاها تزايديا معنوي إحصائيا مقداره 324 فدان سنويا وبمعدل تغير سنوي 4.2\%. وعلي مستوي الأراضي القديمة والجديدة فقد أخذت المساحة المزروعة بالعنب بالأراضي القديمة إتجاها تتاقصيا معنوي إحصائيا خلال فترة الدراسة مقداره 928 فدان علي مستوي الجمهورية بمعدل تغير 1.6\% وأيضا تتاقصيا علي مستوي
عينة الدراسة

يتضح من جدول (2) أن اجمالى المساحة المزروعة

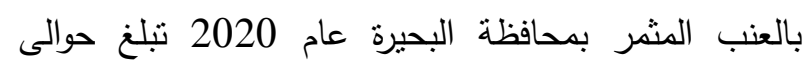

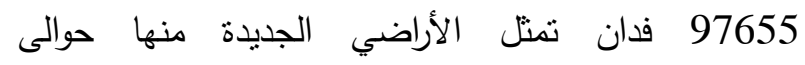
99.24\%، في حين تمنل الأراضي القديمة نحو 0.76\%.

جدول2. الأهمية النسبية للمساحة المزروعة بالعنب المثمر

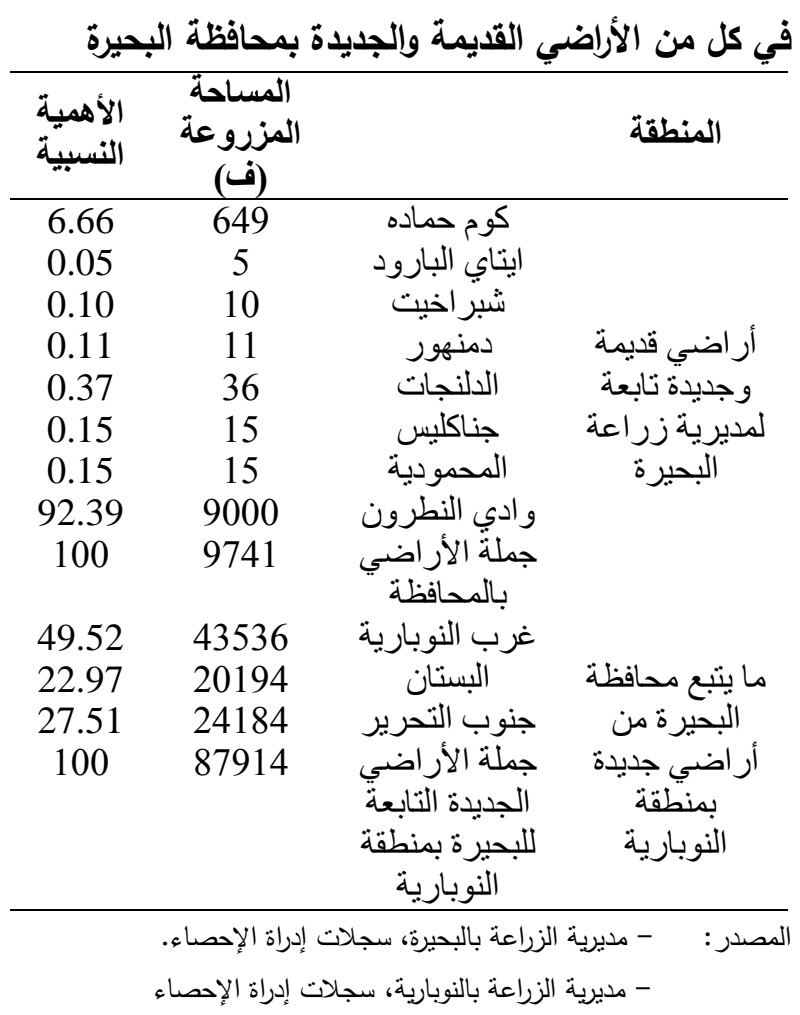

وقد تم إختيار منطقة غرب النوبارية لاختيار عينة الدراسة نظرا لاهميتها النسبية حيث أنها تحنل المرتبة الاولي من حيث المساحة المزروعة بالعنب مقارنة بباقي مناطق الأراضي الجديدة بالبحيرة، حيث تبلغ المساحة المزروعة بالعنب بها 43536 فدان تمنل حوالى 45\% من اجمالى المساحة المرزوعة بالعنب المثمر في الأراضي الجديدة بمحافظة البحيرة. وقد بلغ حجم العينة المختاره 150 مزارع، وقد أجري إختيارهم بأسلوب العينة العشوائية البسيطة من القري ذات الأهمية النسبية في إنتاج العنب بمراقبة غرب 
للعنب قد أخذت إتجاها تتاقصيا غير معنوي إحصائيا علي

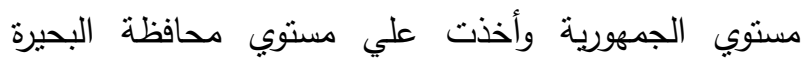
إتجاها تزايديا معنوي إحصائيا بمقدار 0.19 طن للفدان سنويا وبمعدل تغير سنوي 1.64\%. ت ن الثا: الإنتاج تراوح إنتاج العنب في مصرخلال الفترة (2005-2019)

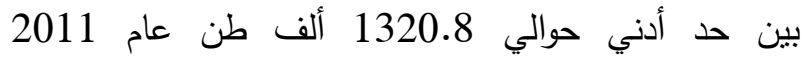
وحدأقصي حوالي 1641.1 ألف طن عام 2018 وبمتوسط سنوي بلغ حوالي 1509.95 ألف طن خلال فترة الدراسة وقد

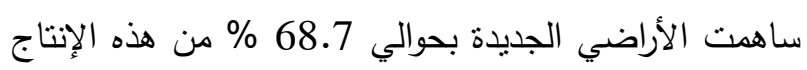
وساهمت الأراضي القديمة بحوالي 31.3\% بحرالي 68.7 منه.

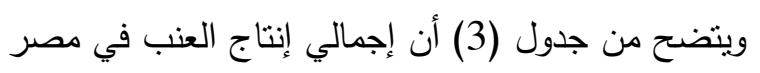

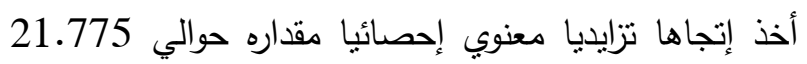

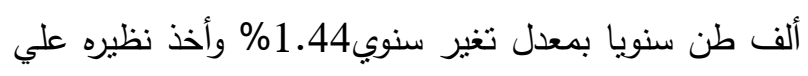
مستوي إجمالي محافظة البحيرة إتجاها تزايديا معنوي إحصائيا مقاره حوالي 5.3 ألف طن سنويا وبمعدل تغير سنوي 6.1 \% أكما يتضح أن إنتاج العنب علي مستوي الأراضي القديمة

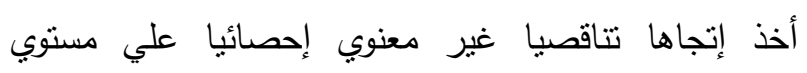

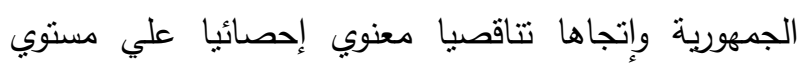

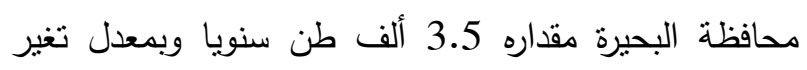
سنوي 14.12\% في حين أخذ علي مستوي الأراضي الجديدة علي مستوي كل من الجمهورية ومحافظة البحيرة إتجاها تزايديا معنوي إحصائيا مقاره 23.6 ألف طن علي من مستوري

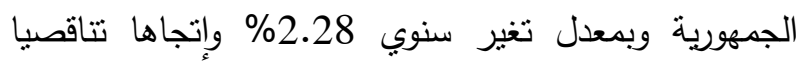
معنوي إحصائيا علي مستوي الأراضي الجديدة بالبحيرة مقداره 780.4 طن سنويا وبمعدل تغير سنوي 6.09\%.
محافظة البحيرة بمقدار 395 فدان وبمعدل تغير سنوي نحو 15.76 \% في حين أخذت نلأك المساحة علي مستوي الأراضي الجديدة إتجاها تزايديا علي مستوي الجمهورية

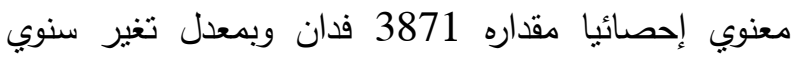
3.68\% وأخذت أيضا علي مستوي محافظة البحيرة إتجاها

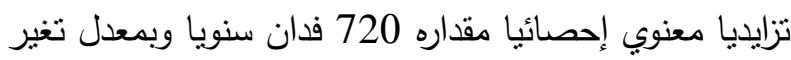
سنوي 13.87\% سنويا. ثانيا : الإنتاجية القدانية تراوح متوسط الإنتاجية الفدانية للعنب علي مستوي الجمهورية خلال الفترة (2005-2019) بين حد أدني حوالي 8.56 طن للفدان عام 2011 وحد أقصي حوالي 9.95 طن للفدان عام 2008 وبمنوسط سنوي بلغ حوالي 9.25 طن للفدان خلال فترة الدراسة، كما بلغ متوسط إنتاجيته

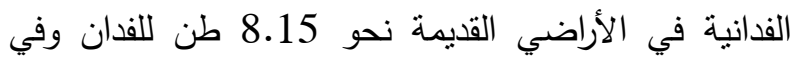

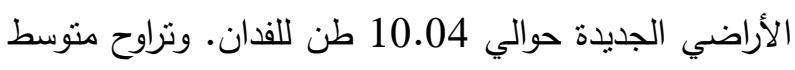

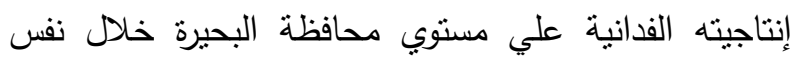
الفتزة بين حد أدني حوالي 9.22 طن للفدان عام 2007 وحد أقصي 13.25 طن للفدان عام 2015 وبمنوسط سنوي بلغ حوالي 11.16 طن للفدان خلال فترة الدراسة. وبتضح من جدول (3) أن نلاك الإنتاجية أخذت إتجاها

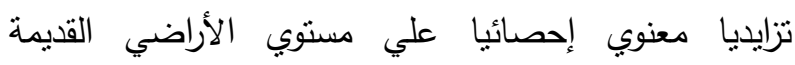
بالجمهورية بمقدار 0.09 طن للفدان وبمعدل تغيرسنوي

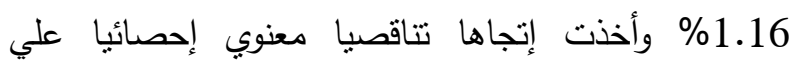
مستوي الأراضي الجديدة مقداره 0.179 طن للفدان وبمعدل تغير سنوي 1.79 \% وأخذت علي مستوي الأراضي القديمة بمحافظة البحيرة إنجاها تزايديا غير معنوي إحصائيا وهو ما يثير إلي الثبات النسبي لها بالأراضي القديمة بمحافظة

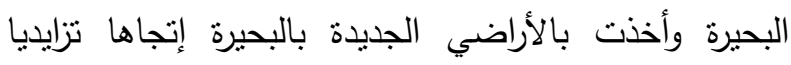
معنوي إحصائيا مقداره 0.42 طن للفدان بمعدل تغير سنوي 3.99 \%. وعلي مستوي متوسط كل من الأراضي القديمة والجديدة فانه يتضح من ذات الجدول أن الإنتاجية الفدانية 
جدول3. معالم معادلات الإتجاه الزمني الخطية للمساحة المزروعة والإنتاجية والإنتاج من العنب علي مستوي الجمهورية ومحافظة البحيرة خلال الفترة (2005- 2019)

(وحدة المساحة بالألف فدان، وحدة الإنتاجية بالطن/ف، وحدة الإنتاج بالألف طن)

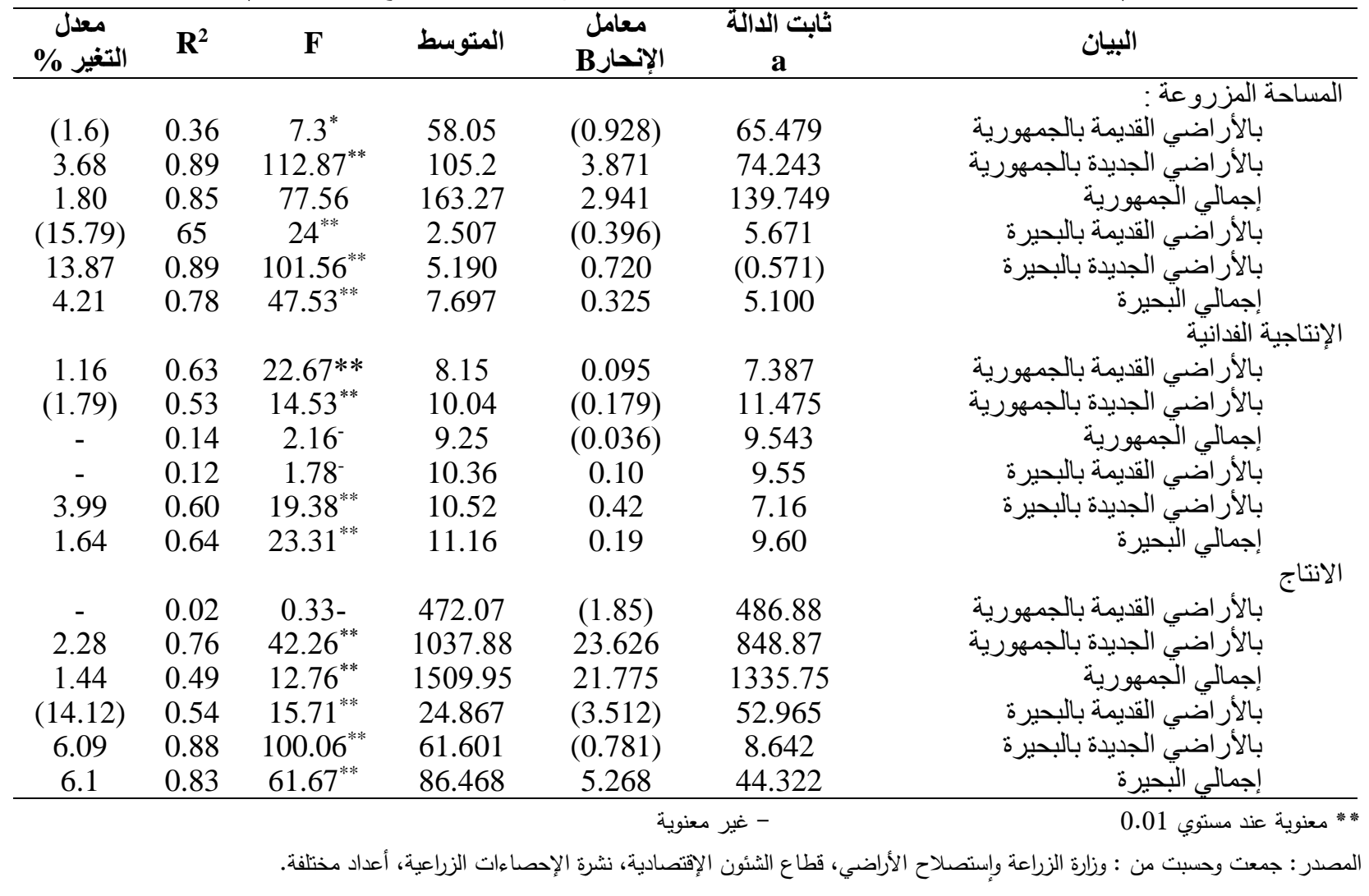

(2) فليم سيدلس: وهو صنف تصديري عديم البذور مبكر النضج والعنقود كبير الحجم والحبة لونها أحمر قرمزي

$$
\text { وينضج في أوائل يونيو · }
$$

(3) كريمسون سيدلس: وهو صنف تصديري عديم البذورمتأخر النضج والعنقود متوسط الحجم مخروطي الثكل والحبة لونها أحمر قرمزي بنضج في أوائل أكتوبر . (4) إيرلي اسبريور: وهو من الأصناف التصديرية المبكرة النضج حيث ينضج في أوائل يونيو ويصدر إلي دول أوروبا حتي منتصف يوليو ويتميز بأن العنقود متوسط الحجم مخروطي الثكل وحباته لونها أبيض مخضر عند
أهم أصناف العنب المزروعة في مصر وسمات كل منها: (m. akhbarelyom.com; https://www.agri2day) يزرع في مصر العديد من أصناف العنب إلا أن الذي يزرع منها بكثرة في مصر ثمانية أصناف هي: (1) البناتي (طومسون سيدلس): وثماره عديمة البذور وهو

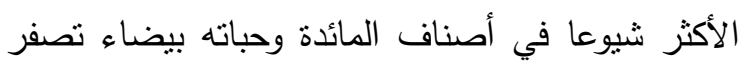
بالنضج وهو من أجود الأصناف لإنتاج الزبيب كما يستخدم في عمل الكمبوست والمربات والعصائر الطازجة وهو من الأصناف مبكرة النضج حيث يظهر في الأسواق أوائل شهر يوليو من الاصناف 
المزروعة به وتقدر إنتاجيته الفدانية بحوالي 8.85 طن للفدان وهي أقل من المتوسط العام بنحو 4.3\% ويمثل إنتاجه نحو 16.5 \% من إجمالي إنتاج العنب في مصر، يليه صنف

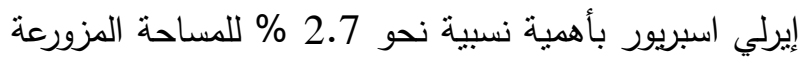
وتقدر إنتاجيته بنحو 11.03 طن للفدان وهي تفوق المتوسط باليط العام بنحو 1\% ويمثل إنتاجه نحو 1.6\% من إجمالي إنتاج العنب يليه أصناف كريمسون و البلدي والفيومي بأهمية نسبية 1.1\% للمساحة المزروعة بهم، وتقدر الإنتاجية الفدانية للكريمسون بحوالي 10.33\% طن للفدان وهي تفوق المتوسط العام بنحو 11.6\% ويمنل إنتاجه نحو 1.2\% من إجمالي

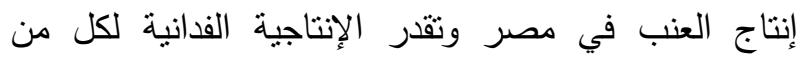
البلاي والفيومي بحوالي 7.38 طن للفدان وهي نقل عن الدتوسط العام بنحو 21.2\% ويمثل إنتاجهما معا نحو 0.9 \% من إنتاج العنب في مصر، يلي ذلأك العنب الغريبي بأهمية نسبية 0.4\% للمساحة المزروعة وتقدر إنتاجيته الفدانية بنحو 8.02 طن للفدان وهي تتخفض عن المتوسط

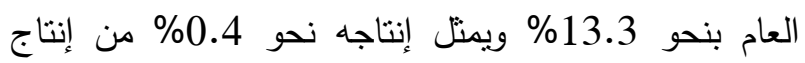
العنب في مصر، يلي ذلك صنف بز العنزة بأهية نسبية 0.3 للمساحة المزروعة وتقدر إنتاجيته بحوالي 4.59 طن للفدان وهي أقل من المنوسط العام بنحو 50.4\% ويمتل إنتاجه نحو 0.2\% من إجمالي إنتاج العنب في مصر. الأهمية النسبية لمختلف بنود تكاليف إنتاج العب بعينة الدراسة : الأنة

يتضح من جدول(5) أن النكاليف الكلية لانتاج فدان العنب بلغت حوالي 57153 جنيها لصنف العنب كريمسون، وحوالي 54338 للفليم سيدلس، وحوالي 43997 جنيها للعنب البناتي، وتمثل إجمالي التكاليف المتغيرة حوالي 68.6\% من التكاليف الكلية للعنب الكريمسون، وحوالي 69.3 للعنب الفليم سيدلس، وحوالي 64.2\% للعنب البناتي. في حين تمتل القيمة الإيجارية للأرض نحو 31.4\%
(5) كينج روبي سيلالس: وهو من الأصناف اللابذرية والعنقود كبيرالحجم مجنح ممتلي جدا والحبة متوسطة منابن الحجم لونها أحمر وردي وهو صنف منأخر النضج ولنج

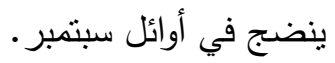

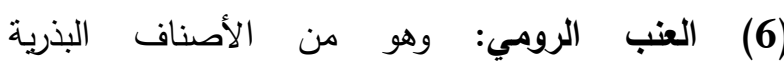
المحليةالمنتشر زراعتها في مصر الوسطي وهو متأخر النضج حيث ينضج في أوائل سبتمبر والعنقود كبير والحبة كبيرة الحجم مستديرة بيضاوية لونها أحمر ورديا. (7) الفيومي: وهومن الأصناف المحلية القديمة والتي كانت تزرع بمساحات كبيرة في محافظة الفيوم والعنقود منوسط الحجم مخروطي قصيرممتلي والحبات مستديرة كروية لونها أخضر فاتح يميل إلي الأصفرار عند النضج ولهات وينضج في منتصف يوليو .

(8) بزالعنزة: من الأصناف البذرية المحلية وتنتشر زراعته في محافظة المنوفية والعنقود متوسط الحجم مدنلئ والحبة بيضاوية طويلة لونها أخضر وينضج في أوائل

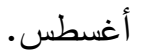

الأهمية النسبية للمساحة المزروعة والإنتاجية والإنتاج لأهم أصناف العنب في مصر: ويتضح من جدول (3) أن العنب البناني (طومسون سيدلس) يأتي في مقدمة الأصناف المزروعة بأهمية نسبية

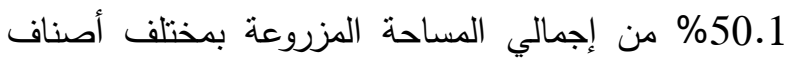
العنب وتتفوق إنتاجيته الفدانية الدقدرة بحوالي 9.68 طن للفدان عن المتوسط العام لإنتاجية جميع الأصناف بنحو 4.6 ويمثل إنتاجه نحو 52.4 \% من إجمالي إنتاج

$$
\text { العنب في مصر · }
$$

يليه العنب الرومي بأهية نسبية 25.5 \% للمساحة المزروعة به وتقدر إنتاجيته الفدانية بنحو 8.72 طن للفدان وهي أقل من المنوسط العام بنحو 5.7\% ، ويمتل إنتاجه نحو 24.1 \% من إجمالي إنتاج العنب في مصر، يليه صنف فليم سيدلس بأهمية نسبية 17.3\% للمساحة 
جدول 4. الأهمية النسبية لمساحة وإنتاجية وإنتاج أهم أصناف العنب عام 2018

\begin{tabular}{|c|c|c|c|c|c|c|}
\hline$\%$ & الإتتاج بالطن & $\%$ & الإنتاجية & $\%$ & المساحة المثُمرة (بالفدان) & الصنف \\
\hline 52.4 & 859868 & 104.6 & 9.679 & 50.1 & 88839 & بناتي \\
\hline 24.1 & 394880 & 94.3 & 8.721 & 25.5 & 45277 & رومي \\
\hline 1.6 & 26806 & 119.2 & 11.031 & 1.4 & 2430 & كينج روبي \\
\hline 0.9 & 14859 & 79.8 & 7.38 & 1.1 & 2011 & بلدي وفيومي \\
\hline 0.4 & 6017 & 86.7 & 8.023 & 0.4 & 750 & غريبي \\
\hline 16.5 & 271469 & 95.7 & 8.854 & 17.3 & 30661 & فليم سيدلَّ \\
\hline 0.2 & 2618 & 49.6 & 4.593 & 0.3 & 570 & بز العنزة \\
\hline 2.7 & 44106 & 99.1 & 9.170 & 2.7 & 4810 & ايرلي اسبريور \\
\hline 1.2 & 19599 & 111.6 & 10.326 & 1.1 & 1898 & كرِيمسون \\
\hline 0.1 & 853 & 69.3 & 6.414 & 0.1 & 133 & أصناف أخري \\
\hline 100 & 1641075 & - & 9.252 & 100 & 177379 & \\
\hline
\end{tabular}

الأسمدة حيث حيث تمثل حوالي 38.2\% من إجمالي التكاليف المتغيرة لصنف الكريمسون حوالي 38.1\% للعنب البناتي ونحو 35\% للفليم سيدلس. وتأتي تكلفة الالي في المرتبة الثالثة بأهمية نسبية 13.8\% من إجمالي التكاليف المتغيرة لصنف الفليم سيدلس ونحو 13.6\% للعنب البناتي ونحو 12.1 بنهيه للعنب الكريمسون. وتأتي في المرتبة الأخيرة تكلفة المبيدات بأهمية نسبية نحو 7.3\% من إجمالي التكاليف المتغيرة لصنف الفليم سيدلس ونحو 6.3\% للكريمسون ونحو 5.6\% للعنب اجنب البناتي
، 350.7\% 35.8 من التكاليف الكلية لكل من تلك الأصناف علي الترتيب.كما يتضح من جدول (5) أن إجمالي تكاليف

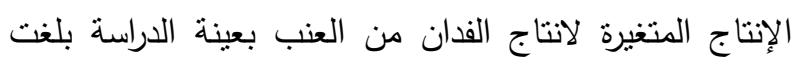
حوالي 39203 جنيها لصنف الكريمسون وحوالي 37638 جنيها لصنف فليم سيدلس وحوالي 28237 جنيها للعنب البناتي.

كما تبين أن تكلفة العمل البشري تحتل المرنبة الأولي بأهمية نسبية حوالي 44.1\% من إجمالي التكاليف المتغيرة لصنف القليم سيدلس ونحو 43.5 \% للكريمسون ونحو 42.6 للعنب البناتي، يليها من حيث الأهمية النسبية تكلفة

جدول5. الأهمية النسبية لمختلف بنود تكاليف الانتاج الفدانية لأهم أصناف العنب بعينة الدراسة (الوحدة: جنيه /فدان)

\begin{tabular}{|c|c|c|c|c|c|c|}
\hline التكاليف من & عنب بناتي & التكاليف من & كريمسون & التكاليف من & سيدلب فليم & 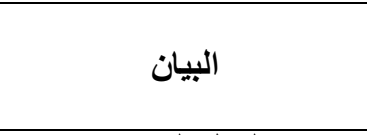 \\
\hline 42.6 & 12042 & 43.5 & 17040 & 44.1 & 16588 & العمل البشري \\
\hline 13.6 & 3850 & 12.1 & 4730 & 13.8 & 5199 & العمل الالي \\
\hline 5.6 & 1570 & 6.3 & 2460 & 7.1 & 2690 & المبيدات" \\
\hline 5.9 & 1680 & 5.3 & 2075 & 6.2 & 2341 & أسمدة عضوية \\
\hline 3.3 & 943 & 2.9 & 1158 & 2.1 & 795 & أسمدة أزوتية \\
\hline 6.8 & 1917 & 5.4 & 2115 & 4.4 & 1650 & أسمدة فوسفاتية \\
\hline 7 & 1975 & 7.4 & 2890 & 6 & 2259 & أسمدة بو تاسية \\
\hline 8 & 2260 & 11.6 & 4540 & 10.8 & 4061 & أسمدة ورقية \\
\hline 7.1 & 2000 & 5.6 & 2195 & 5.5 & 2055 & عناصرصغر ي ومنظمات نمو \\
\hline 38.1 & 10775 & 38.2 & 14973 & 35 & 13161 & إجمالي "الأسمدة \\
\hline \multirow[t]{3}{*}{100} & 28237 & 100 & 39203 & 100 & 37638 & إجمالي التكًاليف المتغيرة \\
\hline & 15760 & & 17950 & & 16700 & الإيجار \\
\hline & 43997 & & 57153 & & 54338 & التكاليف الكلية \\
\hline
\end{tabular}


نظيره للعنب البناتي بنحو 121\% وعن نظيره للفليم سيدلس بنحو 18.7\% وتفوقه للفليم سيدلس عن نظيره للعنب البناتي بنحو 86.1\% ، وهو ما يشير إلي تفوق أربحية صنفي الكريمسون والفليم سيدلس عن العنب البناتي.

\section{خامسا: الهامش الكلي للمزارع}

يتضح تفوق الهامش الكلي للمزارع للصنف كريمسون والمقدر بحوالي 47361 جنيها عن نظيرللفليم سيدلس بنحو 14.4\% وتفوقه للفليم سيدلس عن نظيره للعنب البناتي بنحو

.\%42.6

سادسا : القيمة المضافة للفدان تبين تفوق القيمة المضافة للفدان من العنب الكريمسون والمقدرة بحوالي 69131 جنيها عن نظيرتها للعنب البناتي بنحو 53.8\% وتفوقها عن نظيرتها لصنف الفليم سيدلس بنحو 6.2\% وتقوقها للفليم سبدلس عن البناتي بنحو .\%40.7

\section{سابعا : معدل العائد للتكاليف}

بلغ معدل العائد للتكاليف نحو 151.5\% للعنب الكريمسون ونحو 145.6\% لصنف القليم سيدلس ونحو

$$
\text { 130.2 }
$$

ثامنا : أريحية الجنيه المستثمر:

يتبين أن أربحية الجنيه المستثر في إنتاج فدان العنب بلغت نحو 51.5\% للعنب الكريمسون ونحو 45.6\% للعنب صنف فليم سيدلس ونحو 30.2\% للعنب البناتي وهو ما يثير إلي أن كل جنيه ينفقه المزارع علي إنتاج العنب يحقق أرباحا بلغت حوالي 51 قرشا للعنب الكريمسون وحوالي 45 قرشا للعنب الفليم سيدلس وحوالي 30 قرشا للعنب البناتي.

تاسعا: حافز المنتج للطن من العنب

تبين أن حافز المنتج للطن من العنب بلغ نحو 34\% للعنب صنف كريمسون ونحو 31.3\% لصنف الفليم سيدلس
المؤثرات الاقتصادية لإنتاج أهم أصناف العنب بعينة الدراسةة:

من إستعراض المؤشرات الانتاجية والإقتصادية لأهم أصناف العنب بعينة الدراسة بالأراضي الجديدة بمحافظة البحيرة الواردة بجدول (6) يتضح ما يلي

اولا : الانتاجية الفداتية:

بلغت الإنتاجية الفدانية للعنب صنف كريمسون حوالي 10.531 طن والصنف فليم حوالي 10.340 طن وللعنب البناتي حوالي 8.281 طن وهي نتير إلي تفوق الانتاجية لصنفي كريمسون وفليم سيدلس وهما من الأصناف التصديرية عن نظيرتها للعنب البناتي السائد زراعته بمساحات كبيرة وذلك بنحو 27\% ، 25\% لكل منهما علي الترتيب.

ثانيا: السعر المزرعي

كما يتضح تفوق السعر المزرعي لصنفي كريمسون وفليم سيدلس عن نظيره للعنب البناتي حيث بلغ متوسطه بعينة الدراسة حوالي 8820 جنيه للطن لصنف كريمسون وحوالي 7650جنيها لصنف فليم سيدلس وحوالي 6920 جنيها للعنب البناتي بنسبة زيادة للكريمسون والفليم سيدلس عن العنب البناتي بلغت نحو 18.7\% ،10.5 \% لكل منهما

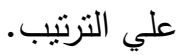
ثالثا: تكاليف الانتاج الكلية بلغت التكاليف الكلية لانتاج الفدان حوالي 57153 جنيها لصنف الكريمسون وحوالي 54338 جنيها للفليم سيدلس وحوالي 43997 جنيها للعنب البناتي بنسبة زيادة لكل من الكريمسون والفليم سيدلس عن البناتي بلغت نحو 29.9\% ، 23.5\% لكل منهما علي الترنيب. رابعا: صافي عائد القدان تبين من الجدول سالف الذكر أعلاه تفوق صافي عائد الفدان المقدر بحوالي 29411 جنيها لصنف الكريمسون عن 
الخطية للاوال المقدة والوارد نتائج تقديرات معالمها بالجدول (3-5) هي أفضل. الصورالمقدرة من الوجهة الاحصائية ووفقا للمنطقة الاقتصادي وفيما مؤشرات المعالم المقدرة من الان الهن

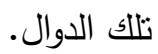
أولا : دالة إنتاج العنب صنف فليم سيدلس يتضح من المعادلة رقم (1) بجدول (7) معنوية الدالة المقدرة عند مستوي 0.01 إستتادا إلي قيمة (F) المقدرة

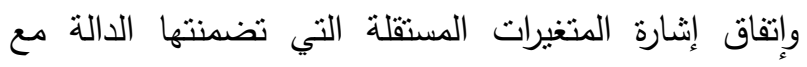

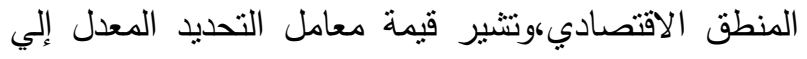

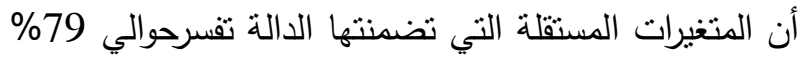

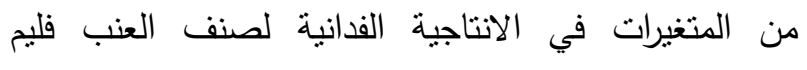

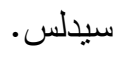

ونحو 23.2\% للعنب البناتي وتثيرتلك النسب إلي صافي العائد الذي يحصل عليه المزارع للطن كنسبة من سعر البيع

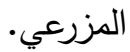
تقدير دوال إنتاج أهم أصناف العب بعينة الدراسة إستتدت الدراسة في تقديرها للتعرف علي ناثير المتغيرات

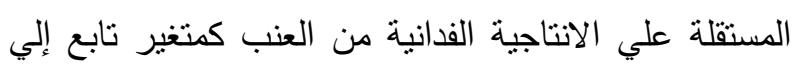

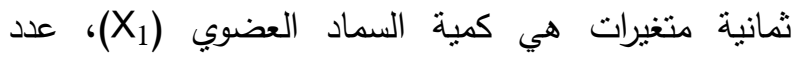
وحدات السماد الفسفوري (X2)، عدد وحدات السماد الأزوتي (X) (X) عدد وحدات السماد البوتاسي (X) نكلفة المغذيات الورقية والعناصر الصغري (X) ) ، عددوحدات العمل البشري

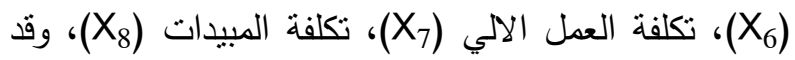

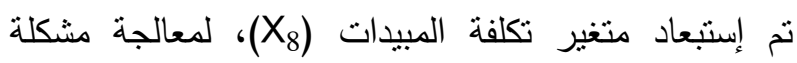
الامتداد الخطي بين المتغيرات المستقلة .كما تبين أن الصورة التعاد

جدول 6. المؤشرات الإقتصادية لانتاج مختلف أصناف العنب بعينة الدراسة (الوحدة بالجنيه)

\begin{tabular}{|c|c|c|c|c|}
\hline عنب فليم سيدلس & عنب كريمسون & 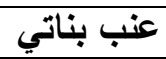 & متوسط الأصناف & 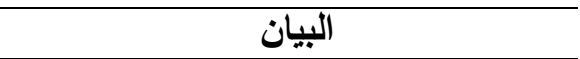 \\
\hline 10.340 & 10.531 & 8.281 & 9.7173 & الانتاجية الفدانية (طن /فدان) \\
\hline 7650 & 8220 & 6920 & 7596.66 & السعر المزرعي للطن \\
\hline 79101 & 86564 & 57304 & 74323 & الإيراد الكلى القدان \\
\hline 54338 & 57153 & 43997 & & التكاليف الكلية (متضمنة الايجار ) \\
\hline 24763 & 29411 & 13307 & 22493.6 & صافي العائد الفداني \\
\hline 2395 & 2793 & 1607 & 2265 & صافي عائد الكلي \\
\hline 41463 & 47361 & 29067 & 39.297 & الهامش الكلى للمزّارع \\
\hline 63250 & 69131 & 44959 & 59113.3 & القيمة المضافَة للفدان \\
\hline 145.60 & 151.5 & 130.2 & 142.43 & نسبة العائد للتكاليف \% \\
\hline 45.6 & 51.5 & 30.2 & 42.43 & أربحية الجنيه المنفق\% \\
\hline \multirow[t]{9}{*}{31.3} & 34 & 23.2 & 29.5 & حافز المنتج للطن من العنب \% \\
\hline & & & & صافي العائد الفاني = الإيراد الكلي - النكاليف الكلية. \\
\hline & & & & صافي عائد الطن = صافي عائد الفذان / الإنتاجية الفانية. \\
\hline & & & & الهامش اكلي للمزارع = الإيراد الكلي - التكاليف المتغيرة. \\
\hline & & & تجارية. & القيمة الدضافة للفان= = الايراد الكلي - تكاليف الدذخلات | \\
\hline & & & 100 & نسبة العائد للنكاليف = (إجمالي العائد /إجمالي النكاليف) × \\
\hline & & & & أربحية الجنيه المنفق = (صافي العائد /إجمالي النكاليف) × \\
\hline & & & البيع المزرعي للطن) × 100 & حافز المنتج للطن من العنب = (صافي العائد للطن / سعر \\
\hline & & & & 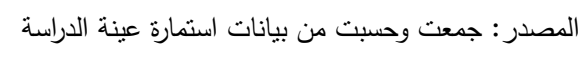 \\
\hline
\end{tabular}


كما تبين وجود تأثير إيجابي معنوي إحصائيا لمتغيرعدد الوحدات المستخدمة من السماد الأزوتي (X) علي الانتاجية

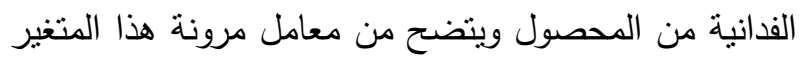

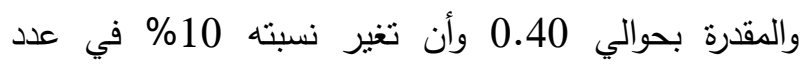
الوحدات المستخدمة من السماد الأزوتي يترتب عليها زيادة

الانتاجية الفدانية لصنف العنب فليم سيدلس بحوالي 4\% كما تبين وجود نأثير معنوي إحصائيا لمتغير عدد وحدات سماد البوتاسوم (X) علي الانتاجية الفدانية للمحصول

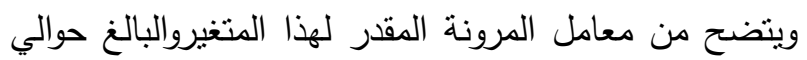
0.11 أن تغير نسبته 10\% في عدد وحدات السماد البوتاسي المستخدمة يترتب عليها زيادة الانتاجية الفدانية اللعنب صنف فليم سيدلس بنحو 1.1\%
كما تبين وجود تأثثر إيجابي معنوي إحصائيا لمتغير عدد وحدات السماد العضوي (X1) علي الانتاجية الفدانية للمحصول ويتضح من معامل المرونة المقدر لهذا المتغير والبالغ حوالي 0.15 أن تغيرا نسبته 10\% في الكيلة الكمية المستخدمة من السماد العضوي يترتب عليها زيادة الانتاجية الفدانية للعنب صنف فليم سيدلس بنحو 1.5\% كما تبين وجود نأثير إيجابي معنوي إحصائيا لمتغيرعدد وحدات التسميد الفوسفاتي (X2) على الانتاجية الفدانية، ويتضح من معامل المرونة المقدر لهذا المتغيروالبالغ حوالي الاتئ 0.19 أن تغير نسبته 10\% في عدد وحدات التسميد الفوسفاتي يترتب عليها زيادة في انتاجيه صنف العنب فليم سيدلس نسبتها 19\%.

جدول 7. معادلات الانحدار المتعدد بين كمية الإنتاج كمتغيرتابع وعدد من المتغيرات المستقلة

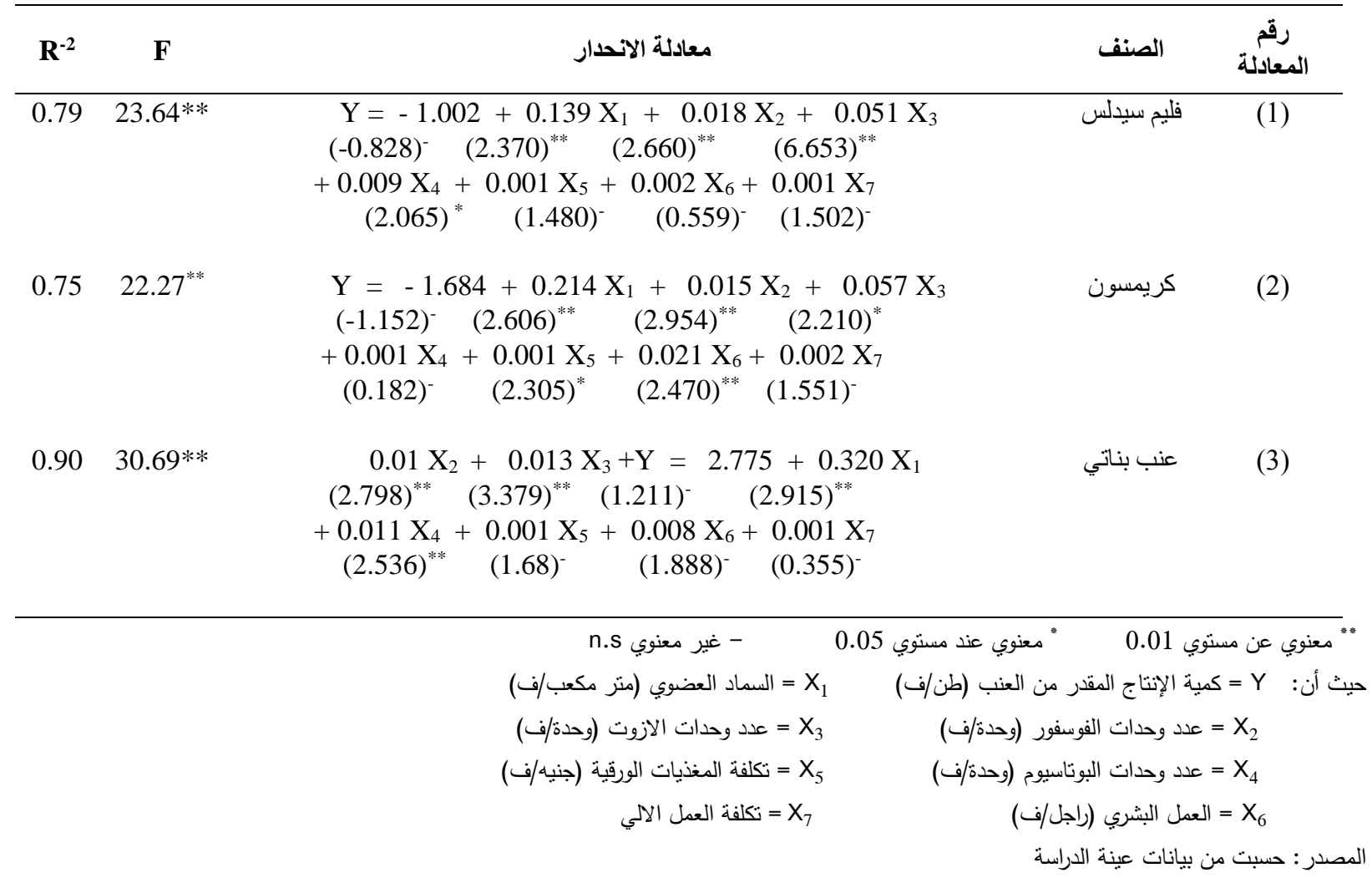


كما نبين وجود نأثير إيجابي معنوي إحصائيا لتاثير عدد

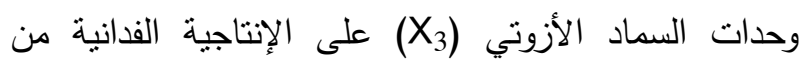
المحصول، ويتضح من معامل مرونة هذا المتغير والمقدرة

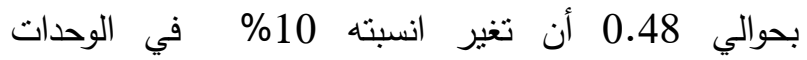
المستخدمة من السماد الأزوتي يترتب عليها زيادة إنتاجية المحصول بنحو 4.8\%. كما تبين وجود تأثنر إيجابي معنوي إحصائيا لتاثير منغير

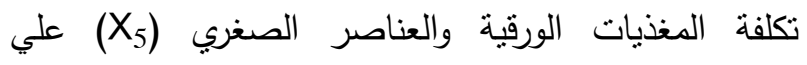
الإنتاجية الفدانية من المحصول، ويتضح من معامل مرونة

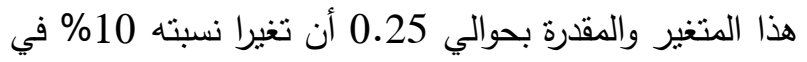
الكمية المستخدمة من المغذيات الورقية والعناصر الصغري يترتب عليها زيادة الإنتاجية الفدانية للمحصول بنحو 2.5\%. كما تبين وجود تأثير إيجابي معنوي إحصائيا لمتغير العمل البشري (X6) على الإنتاجية الفدانية للمحصول، ويتضح من معامل مرونة هذا المتغير المقدرة بحوالي 0.23

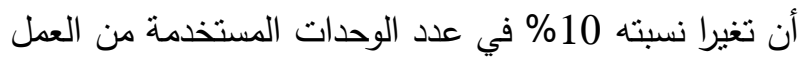
البشري يتزتب عليها زيادة الإنتاجية الفدانية للمحصول بنحو \%2.3

كما تبين وجود تأثنير إيجابي غيرمعنوي إحصائيا لكل من متغير تكلفة المغذيات الورقية والعناصر (X5) ) ، ومتغير تكلفة العمل الالي (X77) على الانتاجية الفدانية للمحصول. كما تبين من تقديرمعامل المرونة الاجمالية للدالة والمقدر بحوالي 2.3 أنها تشير إلي ظاهرة نزايد العائد للسعة أي أن إنتاج العنب صنف كريمسون في عينة الدراسة في المرحلة الأولي للانتاج وهي مرحلة غيرإقتصادية مما يتطلب تكثيف إستخدام المدخلات الإنتاجية والعمل علي تقليل الفاقد الإنتاجي من المحصول.
كما تبين وجود تأثير إيجابي غير معنوي إحصائيا لمتغيرات تكلفة المغذيات الورقية والعناصر الصغري (X) ) كودين عددوحدات العمل البشري (X6) ) ، (X) على الاتتاجية الفدانية من العنب صنف فليم سيدلس. كما تبين من تقدير المرونة الاجمالية للدالة أنها حوالي 1.47 وحيث أنها أكبر من الواحد الصحيح فهي تشير إلي لي ظاهرة تزايد العائد للسعة أي أن إنتاج العنب صنف فليم سيدلس ففي عينة الدراسة يقع في المرحلة الأولي للانتاج وهو مايتطلب زيادة تكثيف إستخدام المدخلات الانتاجية من جانب والعمل علي تقليل الفاقد من المحصول من جانب أخر ثانيا: دالة إنتاج العنب صنف كريمسون يتضح من المعادلة رقم (2) بجدول (7) معنوية الدالة المقدرة عندمستوي 0.01 إستتادا إلي قيمة (F) المقدرة وإتفاق إثنارة المتغيرات المستقلة مع المنطق الاقتصادي ،وتتير إنير قيمة معامل التحديد المعدل إلي أن المتغيرات المستقلة التي تضمنتها الدالة تقسر حوالي 75\% من التغيرات في الانتاجية الفدانية لصنف العنب كريمسون. كما يتبين وجود تأثثر إيجابي معنوي إحصائيا لمتغير كمية السماد العضوي (X1) علي الإنتاجية الفدانية للمحصول ويتضح من معامل المرونة المقدر لهذا المتغير البالغ حوالي 0.22 أن تغيرا نسبته 10\%في كمية السماد العضوي يترتب عليها زيادة الإنتاجية الفدانية للمحصول .\%2.2 كما تبين وجود تأثير إيجابي معنوي إحصائيا لمتغيرعدد وحدات السماد الفوسفوري (X2) على الإنتاجية الفدانية لصنف العنب كريمسون ويتضح من معامل مرونة هذا

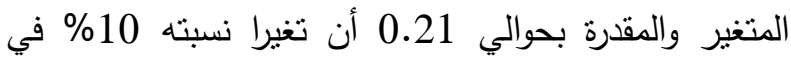
الوحدات المستخدمة من السماد الفوسفوري يترتب عليها زيادة الإنتاجية الفدانية لصنف العنب الكريمسون بنحو 2.1 \% . 
العمل البشري (X) ) وتكلفة العمل الالي (X) الانتاجية الفدانية للمحصول.

كما تبين من تقدير معامل المرونة الاجمالية للاالة

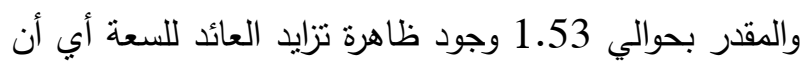
إنتاج العنب البناتي بعينة الدراسة في المرحلة الأولي للانتاج

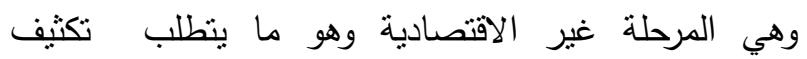
إستخدام الدخخلات الانتاجية والعمل علي تنقليل الفاقد

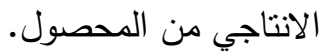

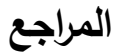

الجهاز المركزي للتعبئة العامة والإحصاء، نشرة التجارة الخارجية

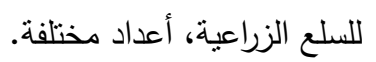

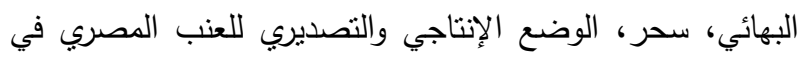
الأسواق العالمية، المجلة المصرية للاقتصاد الزراعي، مجلد

$$
\text { (28) العدد (3) سبتمبر } 2018 .
$$

عطية، عبد القادر محمد عبد القادر ، الحديث في الاقتصاد القياسي بين النظرية والنطبيق، مكتبة الدرار الجامعية بالإسكندرية،

\section{.2005}

مديرية الزراعة بالبحيرة، سجلات إدارة الإحصاء. مديرية الزراعة بالنوبارية، سجلات إدارة الإحصاء.

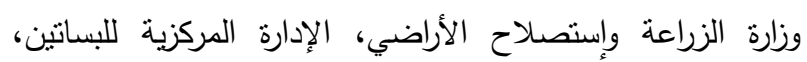

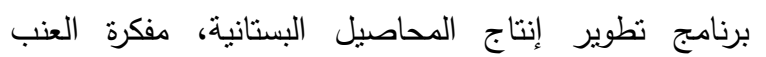

وزارة الزراعة وإستصلاح الأراضي الأراضي، قطاع الثئون الإقتصادية، نشرة الإحصاءات الزراعية، أعداد مختلفة.

m. akhbarelyom.com https://www.agri2day
ثالثا: دالة إنتاج العنب البناتي يتضح من المعادلة رقم (3) بجدول (7) معنوية الدالة

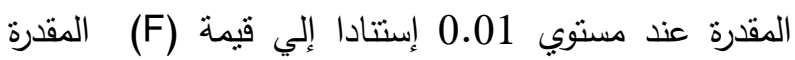

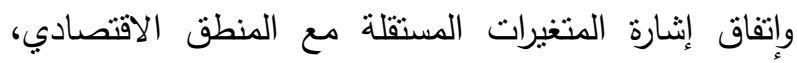
وتثير قيمة معامل التحديد المعدل إلي أن المتغيرات المستقلة التي تضمنتها الدالة تفسر حوالي 90\% من التغيرات في الإنتاجية الفدانية للعنب البناتي.

كما يتضح وجود تأثثرإيجابي معنوي إحصائيا لمتغيرالكمية المستخدمة من السماد العضوي للمحصول، ويتضح من معامل مرونة هذا المتغير المقدرة بحوالي 0.32 أن تغيرا نسبته 10\% في الكمية المستخدمة من هذا النوع من الأسمدة بترتب عليها زيادة الانتاجية الفدانية للمحصول بنحو 3.2\%. كما تبين وجود نأثير إيجابي معنوي إحصائيا لمتغير عدد وحدات السماد الأزوتي (X3) على الإنتاجية الفدانية لللمحصول، ويتضح من معامل مرونة هذا المتغيرالمقدرة بحوالي 0.14 أن نغير نسبته 10\% في الكمية الدستخدمة من هذا النوع من الأسمدة بترتب عليها زيادة الإنتاجية

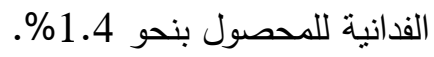
كما تبين وجود تأثير إيجابي معنوي إحصائيا لمتغير عدد

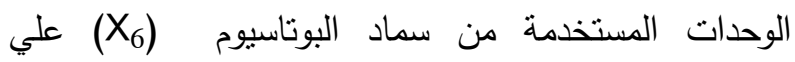
الانتاجية الفدانية للمحصول، ويتضح من معامل مرونة هذا

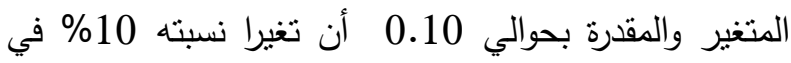
الكمية المستخدمة من هذا النوع من الأسمدة يترتب عليها

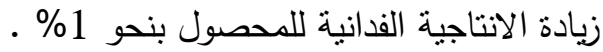

كما تبين وجود تأثير إيجابي غير معنوي إحصائيا لكل من متغيرات عدد وحدات السماد الفوسفوري (X2) ، وتكلفة المغذيات الورقية والعناصرالصغري (X5)، وعدد وحدات 
ABSTRACT

\title{
Efficiency of Resource Use in Producing the Most Important Grape Varieties in the New Lands of Beheira Governorate
}

\author{
Nada R.A. Hamouda, Moustafa M. El-saadany, Afaf A.M. Mohamed, Tamer M. Adlan
}

The research problem is the relative stability of grape productivity despite the high production costs. The research aimed to identify the efficiency of the use of agricultural resources used in its production to identify the economic effects of that problem at the level of the most important varieties cultivated from it in the new lands in Beheira Governorate.

It is clear from the results of the study that the new lands in Egypt contribute about $68.7 \%$ of the grape production in Egypt, and the old lands contribute about $31.3 \%$. It was also found that the production of girl grapes represents about $2.4 \%$ of the total production of grapes in Egypt, followed by the turkey grapes with a relative importance of about $24.1 \%$ and the Flame Seedless by about $16.5 \%$, and the Early Asprior by about $1.6 \%$ and the Crimson by about $1.2 \%$ and each of Fayoumi and Al-Baladi by about $0.9 \%$, followed by that with a contribution The rest of the other items by a small percentage.

It is clear from the economic indicators of the study sample, which included three grape varieties: Banati, Crimson, Flame Seedless, that the net return per feddan amounted to 29,411 pounds for Crimson, 24763 for Flame Seedless, and 13307 for Banati. The profitability of the pound for each of them was about 51.5\%, 45.6\%, and $30.2 \%$, respectively.

The estimation of the grape production function of Flame Seedless cultivar showed a positive and statistically significant effect of each of the organic, phosphate, nitrogen and potassium fertilizers on its feddan productivity
The total elasticity of the function, estimated at about 1.47, indicates the existence of the phenomenon of increasing the return to capacity, that is, the production of grapes of the Flame Seedless variety in the study sample in the initial stage of production, which is not economical.

The estimation of the Crimson grape production function showed a statistically significant positive effect for the same previously mentioned variables, and a statistically significant positive effect for each of the leaf nutrients and human work on its feddan productivity. The overall elasticity of the function (2.3) indicates an increase in the yield to capacity, which means that the production of Crimson grapes in the study sample is in the first stage of production, which is the non-economic stage.

It was found from the estimation of the function of the production of girl grapes that there is a positive effect of the same variables mentioned above on its feddan productivity, and the total elasticity of the function (1.53) indicates an increase in the return to capacity, meaning that the production of girl grapes in the study sample is in the first stage of production, which is the non-economic stage.

Which indicates the need to intensify the use of production elements in the three aforementioned grape varieties to move to the economic stage of production, which is the second stage.

Keywords: Marketing Losses ; Flame Seedless; production costs. 